ENSAIO VISUAL

\title{
Desmontagem ascendente
}

Rodrigo de Araújo a

\begin{abstract}
a Nos anos de 1990, estive ligado à cena musical underground da cidade de São Paulo e me ocupei, sobretudo, da elaboração e da difusão de publicações sobre esta cena. A partir desta paisagem, produzi minhas primeiras ilustrações e colagens associadas ao universo "dark/decadente". As vanguardas do início do século XX (sobretudo da escola Dadaísta) e a explosão pós-punk do final dos anos 70 serviram de referência e impulso para criação de peças autorais em silk screen, colagens digitais e stencil que resultaram no projeto EXQUIS. Tudo que eu queria expressar nos zines e nos primeiros rabiscos consegui sintetizar com mais clareza por meio das colagens disponíveis em diversas técnicas de impressão - desde a artesanal (serigrafia) até a digital. Não apresento apenas objetos de encantamento e sim um convite à ressignificação das formas estabelecidas e libertação do pensamento. A partir da década de 2010, o cinza e o preto de minhas primeiras colagens digitais dão lugar às cores que passam a explorar a corporeidade e a ancestralidade, resultado de meu interesse pela espiritualidade, transcendência e natureza. As colagens apresentadas neste dossiê estão ancoradas em uma reflexão visual sobre a beleza dos corpos ancestrais e a perda da memória decorrente do "encantamento colonial-ocidental". A não expansão do corpo e da mente constitui parte de uma política que, há séculos, promove o achatamento e a supressão dos sentidos. Todos os corpos e todos os povos aqui reverenciados carregam em si sabedorias que transcendem gestos, crenças materialistas e narrativas estritamente racionalistas.
\end{abstract}




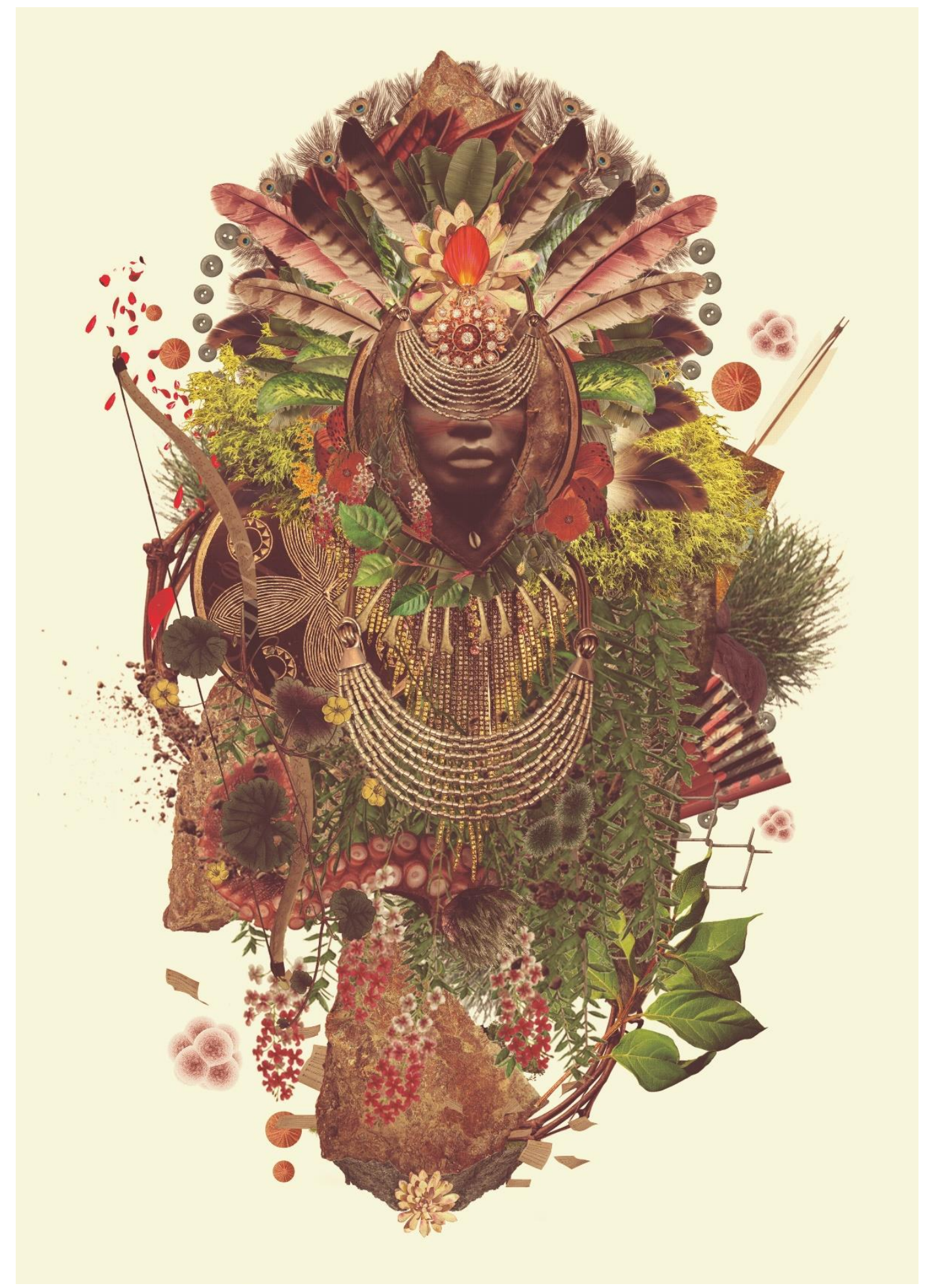

"REI AFRICANO" (2019)

TAMANHO: A4 - 210 x 297 mm

TÉCNICA: COLAGEM DIGITAL 


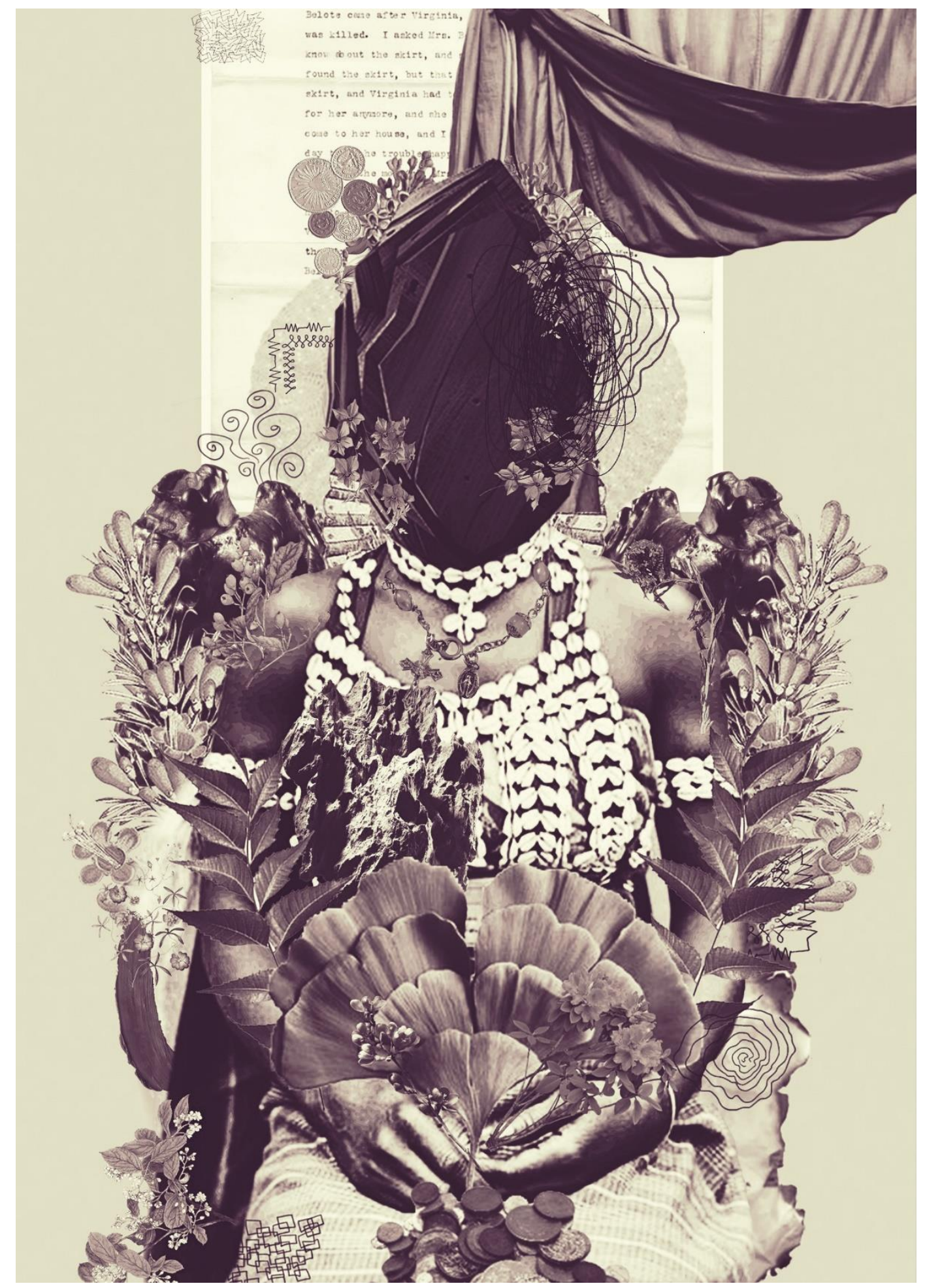

"FÉ" (2021)

TAMANHO: A4 - $210 \times 297 \mathrm{~mm}$

TÉCNICA: COLAGEM DIGITAL 


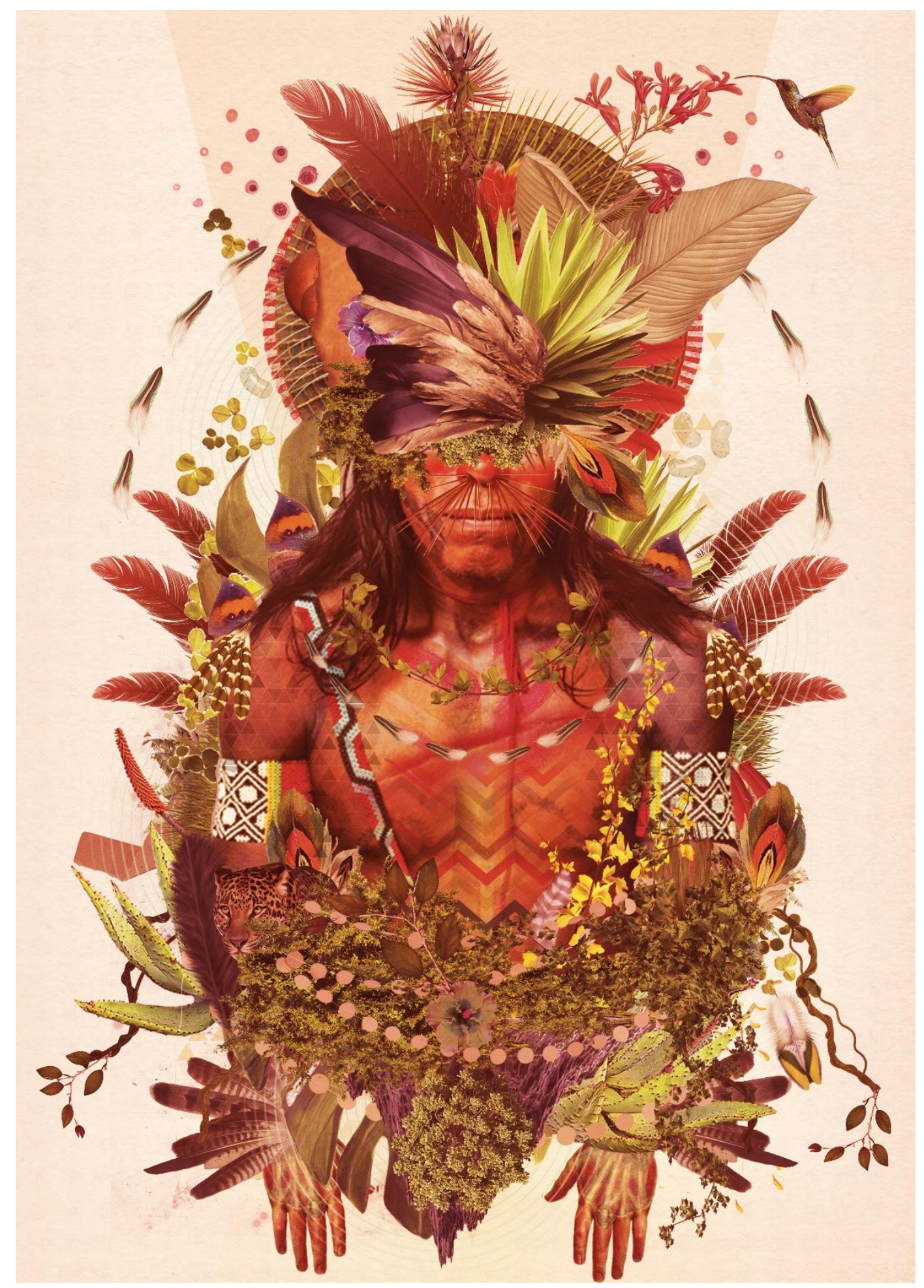

"KAYAPÓ" (2019)

TAMANHO: A4 - $210 \times 297$ mm

TÉCNICA: COLAGEM DIGITAL 


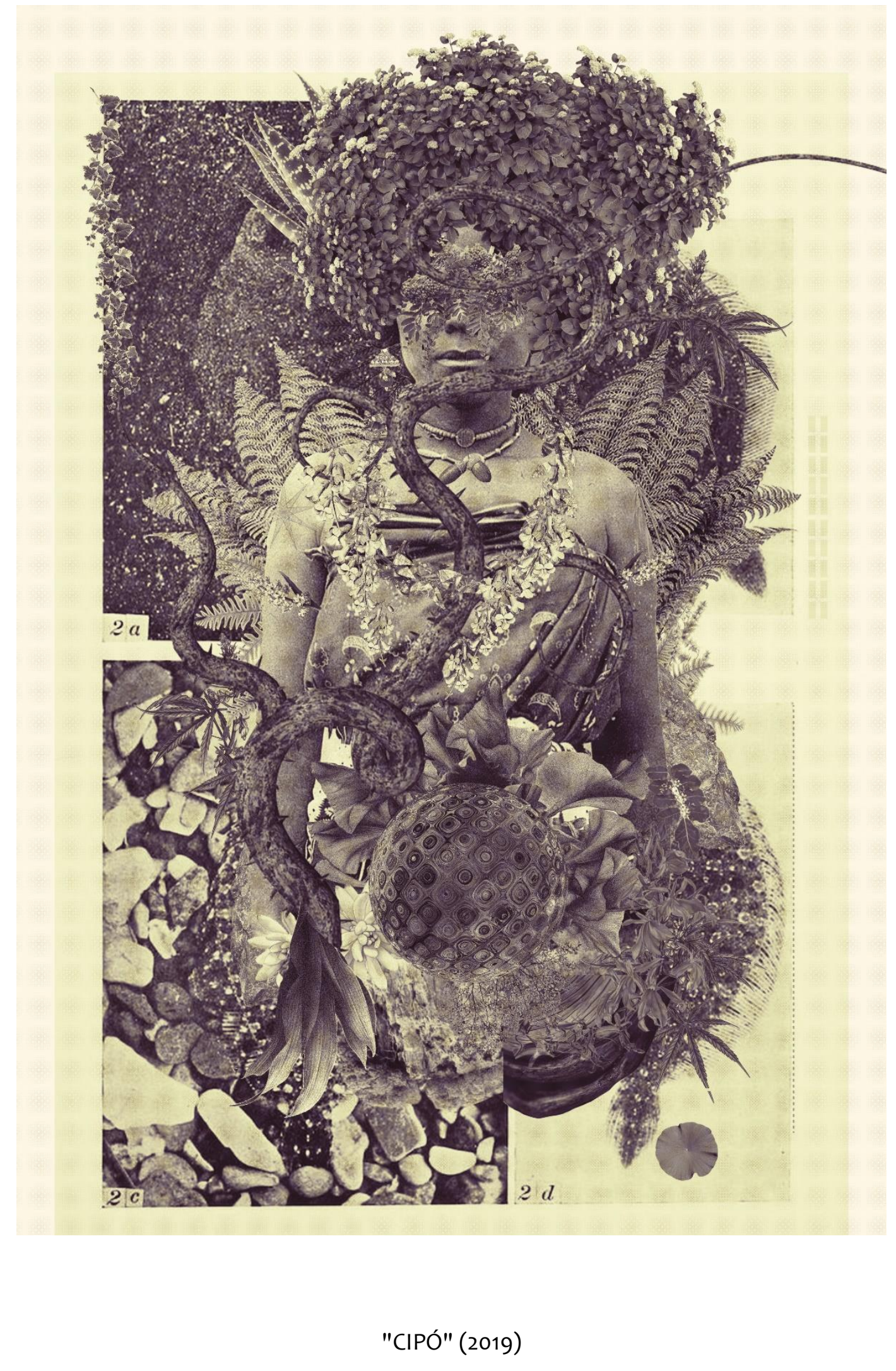

TAMANHO: A4 - $210 \times 297$ mm

TÉCNICA: COLAGEM DIGITAL 


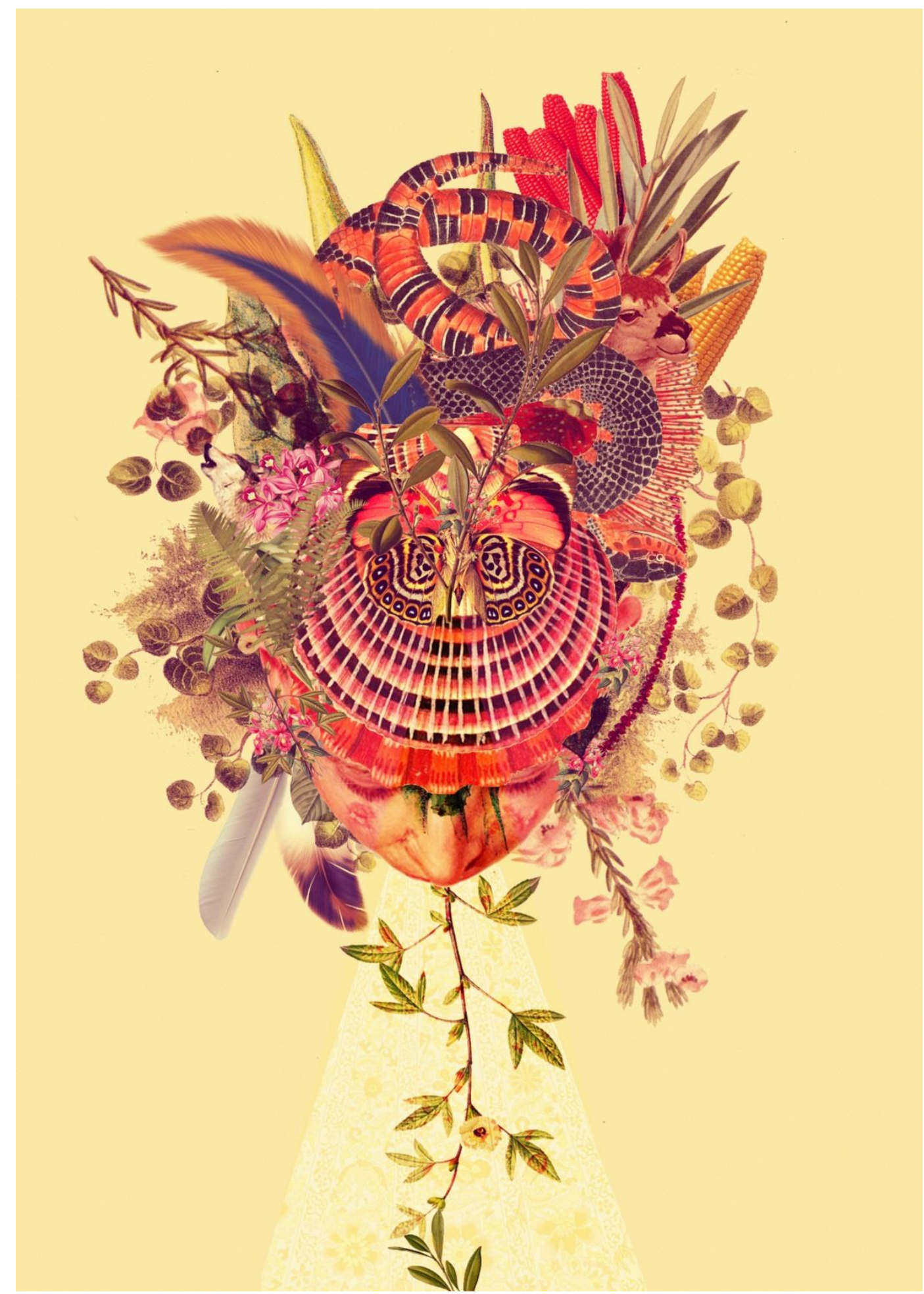

"PACHAMAMA" (2018)

TAMANHO: A4 - 210 x 297 mm

TÉCNICA: COLAGEM DIGITAL 


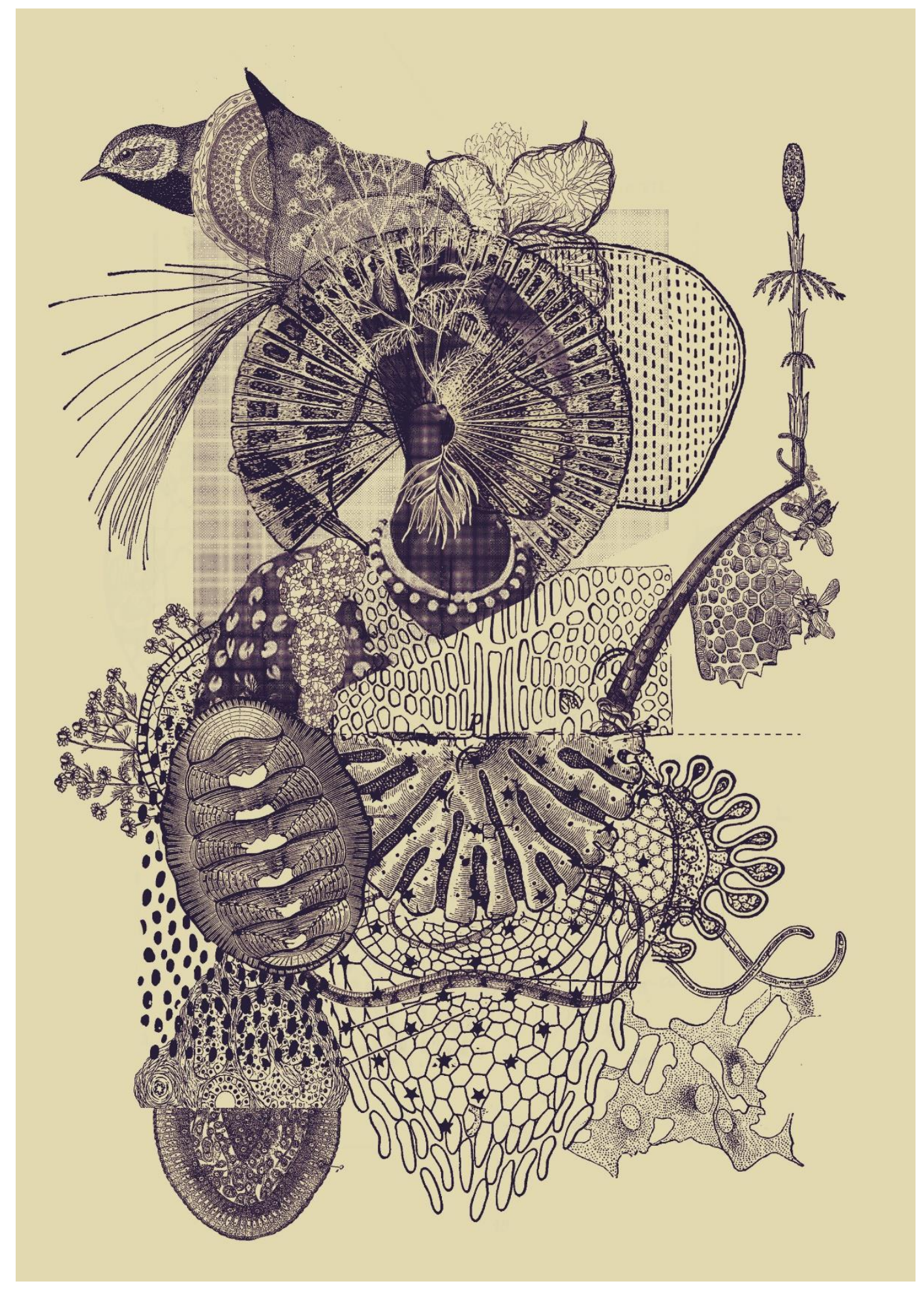

"ORIXA" (2019)

TAMANHO: A4 - 210 x 297 mm

TÉCNICA: COLAGEM DIGITAL 


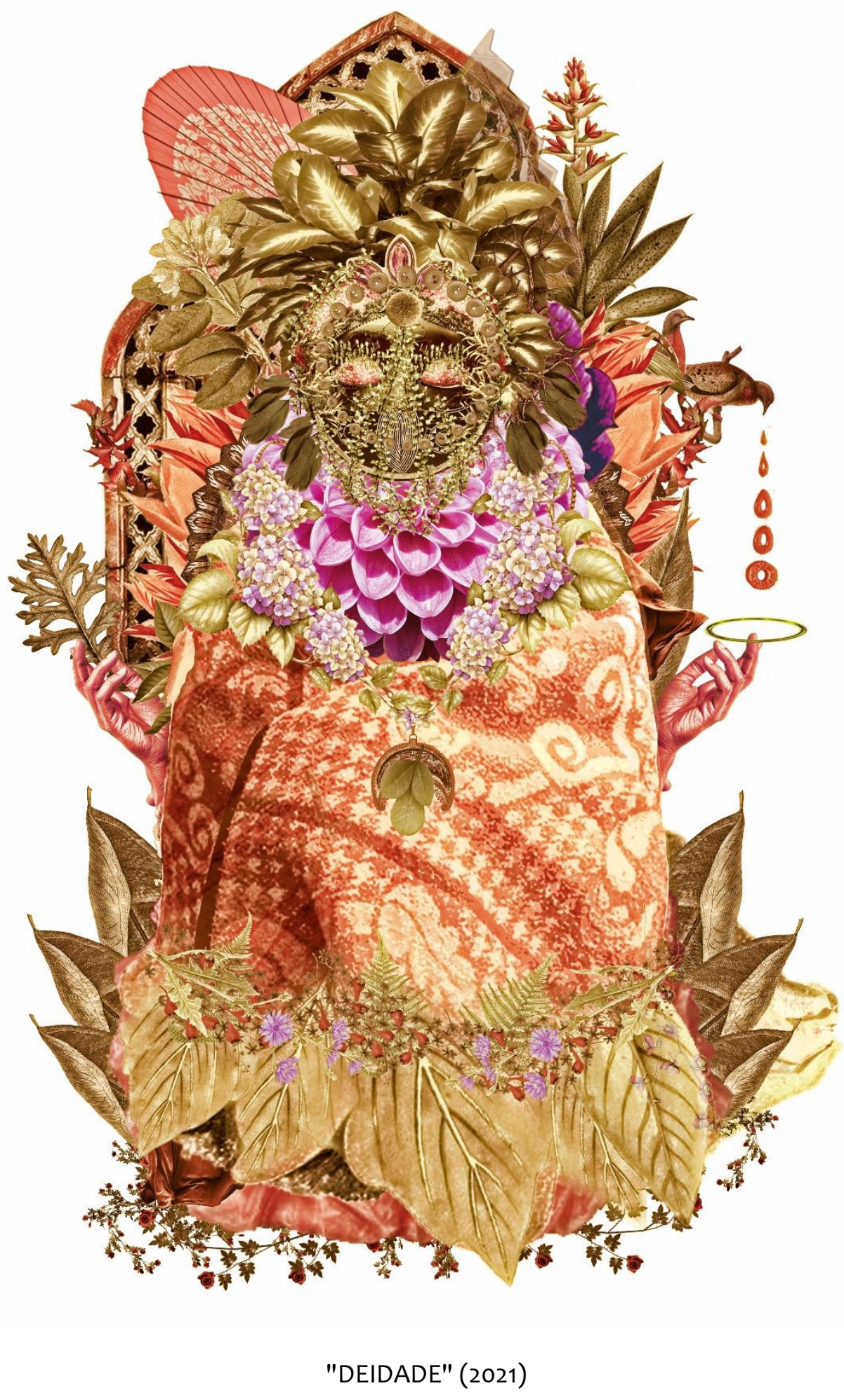

TAMANHO: A4 - 210 x 297 mm

TÉCNICA: COLAGEM DIGITAL 


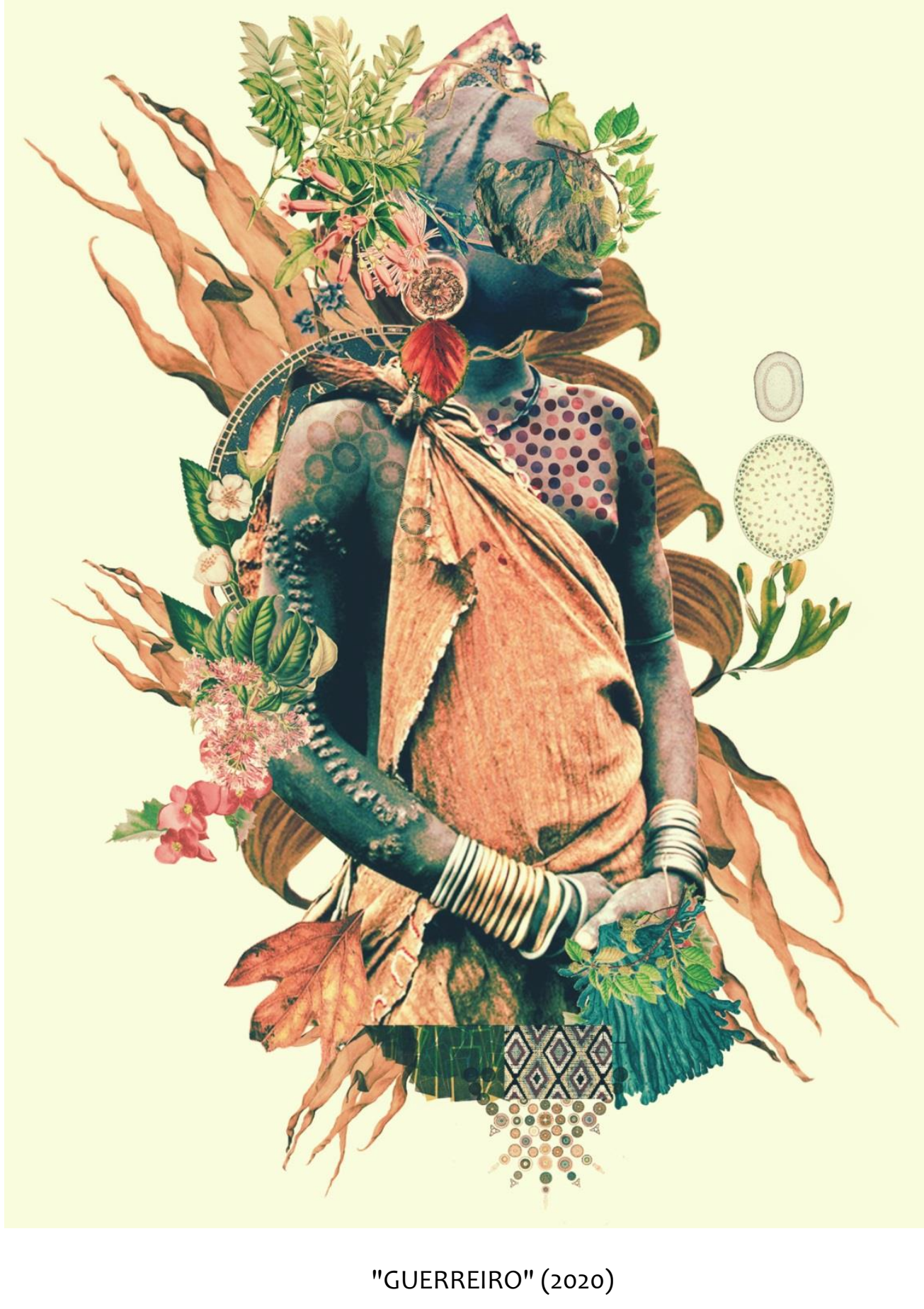

TAMANHO: A4 - $210 \times 297$ mm

TÉCNICA: COLAGEM DIGITAL 